\title{
Detection of Cytomegalovirus in the Meconium of Infected Newborns by Polymerase Chain Reaction
}

\author{
Maria Esterlita T. Villanueva, ${ }^{1}$ David M. Svinarich, ${ }^{2 *}$ \\ Bernard Gonik, ${ }^{2}$ and Enrique M. Ostrea, Jr. ${ }^{1}$ \\ ${ }^{1}$ Department of Pediatrics, Section of Neonatology, Hutzel Hospital, Wayne State University, \\ Detroit, $M I$ \\ ${ }^{2}$ Department of Obstetrics and Gynecology, Wayne State University, Detroit, MI
}

\begin{abstract}
Objective: Congenital cytomegalovirus (CMV) infection is a leading cause of hearing loss and mental retardation throughout the world. Detection of the CMV DNA by polymerase chain reaction (PCR) offers a sensitive, rapid, and specific means of identification. Meconium, the stool formed in utero, may be an ideal specimen for CMV detection. The objective of this study was to develop a PCR-based methodology for the detection of CMV in the meconium of neonates.

Methods: Meconium was collected from 10 newborn infants (seven with positive viral cultures and three uninfected infants born to GMV-seropositive mothers). For each, DNA was isolated from meconium by organic extraction and attachment to a DNA-binding matrix, and PCR was performed using amplimers specific for the major intermediate early (MIE) and late antigenic (LA) regions of CMV.

Results: Gel electrophoresis demonstrated an anticipated PCR product of 250 base pairs (bp) corresponding to the MIE region of CMV in all infected and positive control meconium samples. Furthermore, a single band of 150 bp corresponding to the LA region of CMV was also amplified in several of the infected infants. Conversely, no amplification of these antigenic regions was noted in either uninfected infants born to CMV-seropositive mothers or negative controls.

Conclusions: CMV is present within the meconium of infected neonates and is readily detectable by PCR. Infect. Dis. Obstet. Gynecol. 8:166-171, 2000. ๑ 2000 Wiley-Liss, Inc.
\end{abstract}

DNA amplification; congenital infections; detection strategies

C ytomegalovirus (CMV) is the most common congenital and perinatal viral infection throughout the world, occurring in up to $3 \%$ of all newborn infants. ${ }^{1-3}$ It is the leading cause of sensorineural hearing loss and the most frequently known viral cause of mental retardation. ${ }^{2,3}$ Infection rates in pregnant women have been reported to be as high as $50-80 \% .^{2,3}$ The vertical transmission rate of CMV is approximately $40 \%$ with primary infections and $0.2-1.8 \%$ with recurrent infections. ${ }^{2}$ Although intrauterine infection is common, only $10 \%$ of newborn infants will be symptomatic at birth, with $5-15 \%$ of asymptomatic infants subsequently demonstrating sensorineural hearing loss, mental retardation, microcephaly or motor defects by 2 years of age. ${ }^{2-4}$ Typical cytomegalic inclusion disease in symptomatic infants has a mortality rate of $20-30 \% .^{3}$

Cytomegalovirus is the largest member of the Herpesviridae family, and it has the biological properties of latency and reactivation. Its replicative cycle is divided into an immediate early, early,

*Correspondence to: Dr. David M. Svinarich, Wayne State University School of Medicine, Department of Obstetrics and Gynecology, C.S. Mott Center, 275 East Hancock Avenue, Detroit, MI 48201. E-mail: d.svinarich@wayne.edu 
and late antigenic period. ${ }^{4,5}$ Infection with GMV is currently diagnosed by viral cultures of the infant's urine or amniotic fluid or by measuring immunoglobulin (Ig) M levels. Viral cultures require long incubation times (from 1-2 weeks to as long as 6 weeks), and titer determinations may be of questionable sensitivity. ${ }^{4,6-8}$ Polymerase chain reaction (PCR) is likely the most effective and sensitive method to date for detecting the presence of the virus. ${ }^{6,9-11}$ Polymerase chain reaction amplification is currently used in the diagnosis of a number of intrauterine infections including herpes simplex virus, human immunodeficiency virus, and CMV. Early detection of infection, while viral loads are still low, enables the timely establishment of intervention strategies such as antiviral therapy and early parental counseling. ${ }^{7,12-15}$ To date, no studies have utilized PCR to examine meconium for the presence of pathogens. Fecal samples in general have been one of the least studied clinical specimens by PCR due to the presence of nonspecific inhibitors, which interfere with the amplification reaction. ${ }^{16}$

Meconium consists of desquamated epithelial cells from the intestine and skin, bile, pancreatic secretions, and the residue of swallowed amniotic fluid. Accumulation begins as early as the twelfth gestational week, when fetal swallowing commences. ${ }^{17,18}$ Meconium may therefore serve as a reservoir for viral and bacterial pathogens due to its continuous exposure to the amniotic fluid and fetal urine. ${ }^{16}$ Meconium is a preferred specimen for newborn drug screening since it can detect acute and chronic fetal drug exposure from early midgestation to parturition. ${ }^{17,19}$ The ease of collection, availability up to the third day of postnatal life, and continual bioconcentration of meconium prompted the development of a PCR-based methodology that would enable the examination of meconium for the presence of CMV.

\section{METHODS Collection of Meconium}

Meconium samples used as controls and in spiking experiments were collected from normal newborn infants born to uninfected mothers. Meconium was also collected from 10 newborn infants born to CMV IgG-seropositive mothers. Seven of these infants were diagnosed as CMV-positive by culture (six by urine culture and one by amniotic fluid but negative urine culture), and three infants had urine cultures negative for GMV. The meconium was stored at $-70^{\circ} \mathrm{C}$ until used. Sample collection was conducted in accordance with guidelines established by the institutional Human Investigation Committee at the time these experiments were conducted.

\section{Extraction of DNA From Meconium}

Meconium $(0.05 \mathrm{~g}$ and $0.5 \mathrm{~g})$ was dissolved in 10 volumes (w/vol) of Tris-HCl buffer $(\mathrm{pH} \mathrm{8.0)}$ and centrifuged at $2,000 \mathrm{~g}$ for 10 minutes to remove particulate matter. Proteinase $\mathrm{K}(20 \mathrm{mg} / \mathrm{mL})$ and sodium dodecyl sulfate $(10 \%)$ were added to $500 \mu \mathrm{L}$ of the supernate and subsequently incubated in an orbital shaker at $55^{\circ} \mathrm{C}$ for 18 hours at $125 \mathrm{rpm}$. The supernatants were extracted thrice with equal volumes of chloroform:isoamyl alcohol:phenol (25:24: 1) and twice with equal volumes of isobutanol. DNA was then absorbed to a DNA binding matrix (Quantum Prep Plasmid miniprep kit, Bio-Rad Laboratories, Hercules, CA) per manufacturers' instructions and eluted from the matrix with two 50$\mu \mathrm{L}$ aliquots of sterile $50^{\circ} \mathrm{C}$ water. The eluate was subsequently stored at $-20^{\circ} \mathrm{C}$ until needed.

\section{PCR Amplification of CMV DNA}

The PCR amplification was conducted in a $50-\mu \mathrm{L}$ reaction volume containing Taq DNA polymerase buffer (Promega Corporation, Madison, WI), amplimers $(1.0 \mathrm{mmol} / \mathrm{L})$ from either the major intermediate early (MIE) region (5'-CCACCCGTGGTGCCAGCTCG-3', 5'-CCCGCTCCTCCTGAGCACCC- $\left.3^{\prime}\right)$ or the late antigenic (LA) region (5'-CGGTTCAGGGTCAGAATCTG-3' , 5' CGATACGCGTTGCAATTCGG-3') (Integrated DNA Technologies, Inc., Coralville, IA) of CMV, $\mathrm{MgCl}_{2}(2.5 \mathrm{mmol} / \mathrm{L}), \mathrm{dNTPs}(0.2 \mathrm{mmol} / \mathrm{L})$, and a $5.0-\mu \mathrm{L}$ aliquot of the DNA-containing eluate. ${ }^{20}$ The PCR reaction mixture was subsequently overlaid with $50 \mu \mathrm{L}$ of sterile mineral oil (Sigma Chemical Co., St. Louis, MO). The template was initially denatured for 5 minutes at $94^{\circ} \mathrm{C}$ before the addition of two units of Taq DNA polymerase (Perkin-Elmer, Norwalk, C'T). Amplification was conducted in a Perkin-Elmer thermocycler (Perkin-Elmer) for 40 cycles at a denaturation temperature of $94^{\circ} \mathrm{C}$ for 2 minutes, an annealing temp of $65^{\circ} \mathrm{C}$ for 90 seconds, and an extension temperature of $72^{\circ} \mathrm{C}$ for 90 seconds. This was followed by a terminal extension time of 10 minutes at $72^{\circ} \mathrm{C}$. 


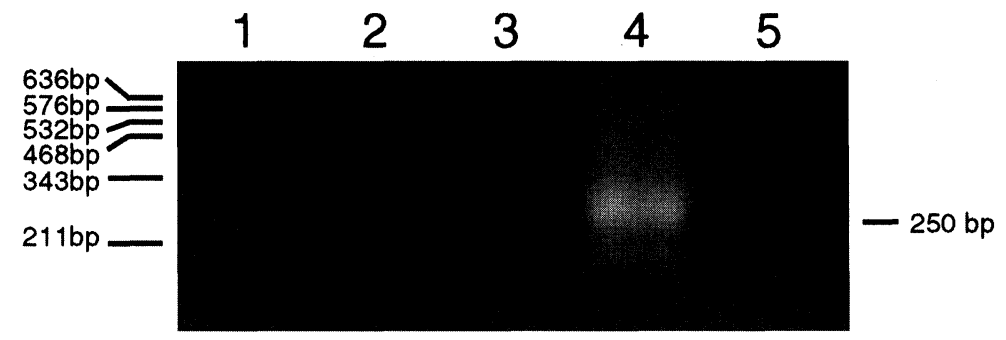

Fig. I. Detection of CMV MIE antigenic region from spiked meconium. PCR amplification yielded a 250-bp product from 0.05 $\mathrm{g}$ (lane I), $0.5 \mathrm{~g}$ (lane 2) of meconium spiked with $100 \mu \mathrm{L}$ of CMV ADI69 stock culture and a PCR positive control (lane 4). No product was amplified from either the negative meconium control, $0.5 \mathrm{~g}$ (lane 3), or the negative PCR control (lane 5). The location of the amplified PCR product is indicated on the right.

The PCR products were subsequently resolved by agarose gel electrophoresis. Amplimers to the MIE and LA antigenic regions of the virus were used to ensure detection of virtually all wild types of CMV. ${ }^{20}$ The positive meconium control consisted of extracts from meconium $(0.5 \mathrm{~g})$ that was spiked with $100 \mu \mathrm{L}$ of heat-inactivated CMV strain AD169 stock culture. Positive PCR controls contained CMV DNA isolated directly from the CMV AD169 stock culture. Negative meconium controls contained meconium extracts from uninfected infants, and negative PCR reactions had water substituted for template DNA.

\section{RESULTS \\ Detection of CMV From Spiked Meconium Samples}

Meconium $(0.05 \mathrm{~g}, 0.5 \mathrm{~g})$ spiked with $100 \mu \mathrm{L}$ of CMV AD169 stock culture yielded an anticipated product of 250 base pairs (bp) following DNA extraction and PCR amplification with the MIE amplimers of CMV (Fig. 1). A similar product was obtained from the PCR positive control. Conversely, no amplification was obtained from either the negative meconium or negative PCR control.

\section{Detection of CMV in the Meconium of Infected Infants}

The PCR amplification using amplimers specific to the MIE region of CMV yielded a 250-bp product from six patients who had CMV-positive urine. Amplification was also observed from the meconium of one patient who was negative for CMV by urine culture but had CMV-positive prenatal amniotic fluid by culture (Fig. 2). The PGR amplification of the LA region of CMV yielded a 150-bp product from three out of six patients with positive urine cultures and the single patient with a negative urine culture but positive prenatal amniotic fluid culture (Fig. 3). In both experiments PCR products of $250 \mathrm{bp}$ and $150 \mathrm{bp}$ were amplified from the CMV AD169 culture using the MIE and LA amplimers, respectively. Conversely, no amplification was observed in either the PCR or meconiumnegative controls.

The presence of CMV in three culture-negative patients born to CMV IgG-seropositive mothers was also examined using amplimers to the MIE and LA regions of CMV (Figs. 4, 5). In each instance, PCR amplification failed to demonstrate the presence of CMV in the meconium of infants born to these CMV-infected mothers. Appropriate PCR products of $250 \mathrm{bp}$ and $150 \mathrm{bp}$ were observed following amplification of positive controls with MIE and LA amplimers, respectively. No PCR products were amplified from the negative meconium or PCR controls.

\section{DISCUSSION}

The pathobiology of CMV infection has been well documented, but virtually nothing is known about the appearance of CMV or other pathogens in meconium, which was long considered to be a sterile medium. The detection of pathogens in meconium by PCR has been hindered by the presence of nonspecific inhibitors that preclude DNA amplification. As a result, little is known about the ability of meconium to serve either as a reservoir for infectious agents acquired in utero or the utility of meconium to serve as a diagnostic specimen.

This report is the first to describe both the detection of CMV in meconium and a methodology 


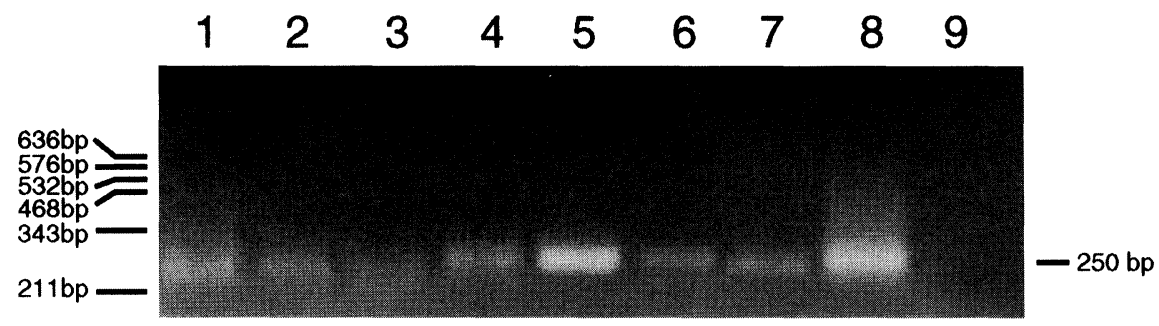

Fig. 2. Detection of the CMV MIE antigenic region in CMV-positive patients. Meconium from six neonatal patients with CMV-positive urine (lanes 1-6) and one patient with CMV-negative urine and CMV-positive amniotic fluid (lane 7) were examined. PCR amplification yielded a 250 -bp fragment in all patients examined and a positive PCR control (lane 8 ). No product was amplified from the negative PCR control (lane 9).

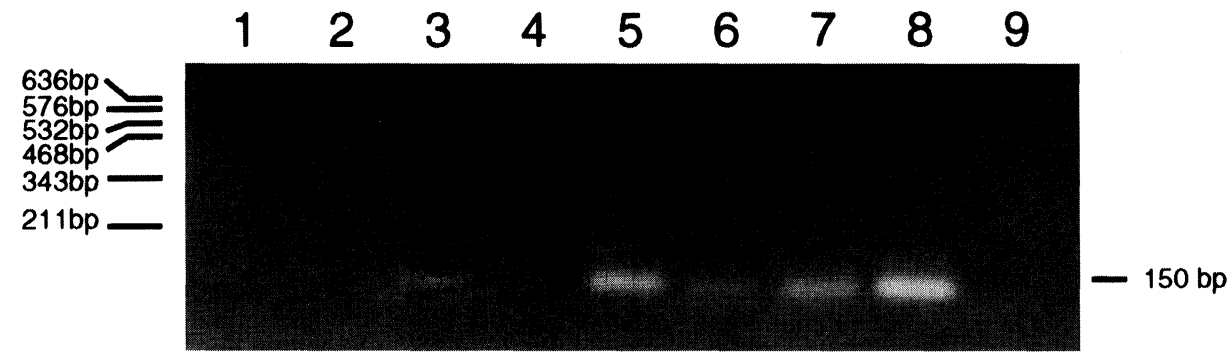

Fig. 3. Detection of the CMV LA antigenic region in CMV-positive patients. Meconium from six neonatal patients with CMV-positive urine (lanes I-6) and one patient with CMV-negative urine and CMV-positive amniotic fluid (lane 7) were examined. PCR amplification yielded a I50-bp fragment in four patients examined (lanes 3, 5, 6, 7) and a positive PCR control (lane 8). No product was amplified from the negative PCR control (lane 9).

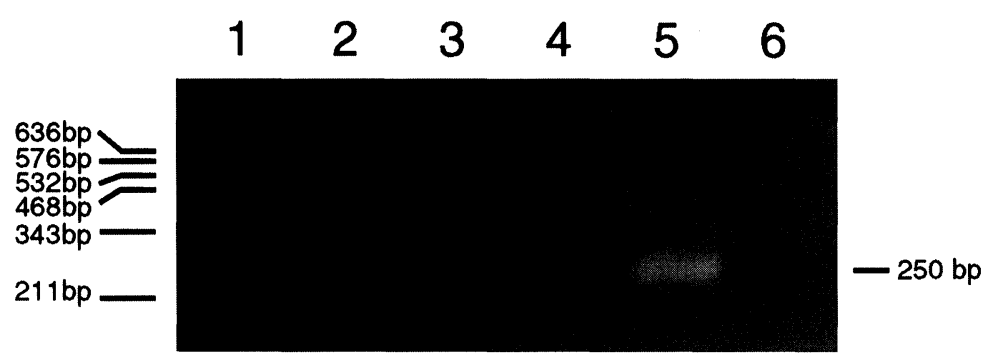

Fig. 4. Detection of the CMV MIE antigenic region in CMV-negative neonatal patients born to CMV-positive mothers. Meconium from three CMV-negative neonatal patients born to CMV-positive mothers was prepared for analysis by PCR. PCR amplification failed to yield any product in either the patient samples (lanes I-3) or the negative meconium control (lane 6). The positive PCR control yielded an anticipated product of 250 bp (lane 5).

that allows the isolation of relatively intact viral DNA from meconium that is suitable for PCR amplification. The use of PGR amplification following organic extraction coupled with binding to a DNA binding matrix enables the rapid and sensitive detection of CMV in the meconium of newborn infants infected in utero. The faster turnover time (24-36 hours) as well as the use of very small amounts of meconium are additional advantages of this PCR strategy over conventional viral culture techniques. Detection of CMV by PCR from specimens other than urine may provide important predictions for the development of systemic disease. ${ }^{21}$ For instance, performing PCR analysis and Southern hybridization on blood obtained from filter paper utilized in newborn screening has revealed a detection rate for CMV of $25 \%$ in healthy newborns and $33 \%$ in low-birthweight infants. These rates are markedly higher than the known rate of congenital GMV infection. ${ }^{7}$ Likewise, PGR per- 


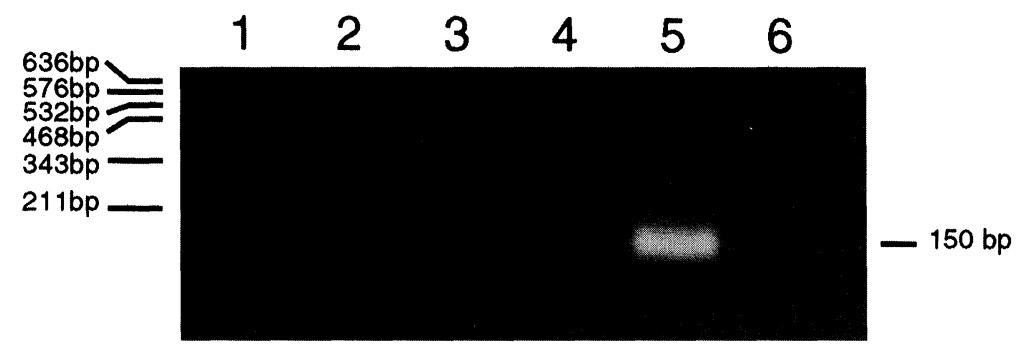

Fig. 5. Detection of the CMV LA antigenic region in CMV-negative neonatal patients born to CMV-positive mothers. Meconium from three CMV-negative neonatal patients born to CMV-positive mothers was examined. PCR amplification failed to yield any product in either the patient samples (lanes I-3) or the negative meconium control (lane 6). The positive PCR control yielded an anticipated product of 150 bp (lane 5).

formed on chorionic villi revealed that $23 \%$ of all samples tested positive for CMV. These findings suggest both a higher transmission rate during early pregnancy as well as an association with significant fetal abnormalities or wastage. ${ }^{3,21}$ Meconium, which begins forming early in gestation, may be a better specimen than urine for the identification of CMV infections that occurred early in pregnancy because viral shedding in the urine may have stopped at the time of birth.

With these data, we introduce an isolation strategy that enables the detection and amplification of CMV DNA from meconium. We have also demonstrated the presence of CMV via PCR technology in the meconium of infected neonates. The sensitivity and specificity of this methodology will need to be confirmed using a larger cohort of newborns. Additionally, these comparisons must be made against the accepted laboratory-based gold standards such as viral culture as well as against actual clinical disease. Several limitations to this approach are acknowledged. First, the possibility of neonatal swallowing of contaminated maternal secretions during delivery is a concern. In this regard, utilizing a first-passage sample of meconium may be more representative of the in utero environment. Following delivery, while contamination of meconium with neonatal urine is possible, every precaution was taken to avoid this in the samples collected. Of note is the detection of CMV from a neonate with a positive amniotic fluid culture but a negative urine culture. Although PCR of the urine may have yielded concordant results, the positive meconium PCR in this case opens an interesting area of virologic study. Does this represent digested debris in a neonate exposed to but not infected with CMV? Conversely, does this represent an early in utero infection with systemic clearing of the virus? Unfortunately, neonatal serologic studies were not available in this case to help differentiate these possibilities. We hope that future studies with this new approach, utilizing a readily available fetal byproduct (that serves as a reservoir for the in utero environment throughout most of pregnancy), will provide additional insight into the natural history of this common fetal pathogen.

\section{ACKNOWLEDGMENT}

The authors would like to acknowledge Bio-Rad Laboratories for their gift of Quantum Prep Mini$\operatorname{prep}^{\mathrm{TM}}$ binding matrix.

\section{REFERENCES}

1. Numazaki K. Human cytomegalovirus infection of breastmilk. FEMS Immunol Med Microbiol 1997;18: 91-98.

2. Stamos J, Rowley A. Timely diagnosis of congenital infection. Pediatr Clin North Am 1994;41:1017-1033.

3. Yari D, Gull I, Peyser M, Lessig JB. Congenital cytomegalovirus infection. Eur J Obstet Gynecol Reprod Biol 1995;63:7-16.

4. Nelson CT, Demmler G. Cytomegalovirus infection in the pregnant mother, fetus and newborn infant. Clin Perinatol 1997;24:151-160.

5. Espy M, Smith T. PCR detection of cytomegalovirus DNA sequences in clinical specimens. In: Persing DH, Smith S, Tenover FC, White TJ, editors. Diagnostic molecular biology. principles and applications. Washington, DC: American Society of Microbiology, 1993, pp 350-355.

6. Schafer P, Laufs R. Experience with quantitative PCR for the management of HCMV. Intervirology 1996;39: 204-212.

7. Shibata M, Takano H, Hironaka T, Hirai K. Detection of human cytomegalovirus DNA in dried newborn blood filter paper. J Virol Methods 1994;46:279-285.

8. Miller M, Bovey S, Pado K, et al. Application of PCR to multiple specimen types for diagnosis of cytomegalovi- 
rus infection: Comparison with cell culture and shell vial assay. J Clin Microbiol 1994;32:5-10.

9. Scifert G. Diagnosis of cytomegalovirus disease in biopsy and surgical material: Methods and clinical relevance. Pathologie 1997;18:207-217.

10. Ehrnst A. The clinical relevance of different laboratory tests in CMV diagnosis. Scand J Infect Dis Suppl 1996; 100:64-71.

11. Bowen EF, Griffith PD, Davey CC, et al. Lessons from the natural history of cytomegalovirus. AIDS 1996;10: S27-41.

12. Templeton $\mathrm{N}$. The polymerase chain reaction. Diagn Mol Pathol 1992;1:58-72.

13. Puchhammer- Stock E, Kunz C, et al. Detection of varicella zoster virus DNA in fetal tissue by polymerase chain reaction. J Perinat Med 1994;22:65-69.

14. Schleninger Y, Storck G. Herpes simplex meningitis in infancy. Pediatr Infect Dis J 1994;13:141-144.

15. Suarez M Jr., Blanco B, Breon L, et al. A rapid test for the detection of human immunodeficiency virus antibodies in the cord blood. J Pediatr 1993;123:259-261.

16. Grimpel E, Sanchez P, Wendel G, et al. Use of poly- merase chain reaction and rabbit infectivity testing to detect $T$. pallidum in amniotic fluid, fetal and neonatal sera and cerebrospinal fluid. J Clin Microbiol 1991;29: 1711-1718.

17. Ostrea EM. Meconium drug analysis. In: Lewis M, Bendrsky M, editors. Mothers, babies and cocaine. The role of toxins in development. Hillsdale, NJ: Lawrence Erlbaum Associates, 1995, pp 179-202.

18. Ostrea EM, Romero A, Knapp DK, et al. Postmortem drug analysis of meconium in early-gestation human fetuses exposed to cocaine: Clinical implication. J Pediatr 1994;124:477-479.

19. Mahone PK, Scott G, Sleggs T, et al. Cocaine and metabolites in amniotic fluid may prolong fetal drug exposure. Am J Obstet Gynecol 1994;171:465-469.

20. Flint A, Frank TS. Cytomegalovirus detection in lung transplant biopsy samples by polymerase chain reaction. J Heart Lung Transplantation 1994;13:38-42.

21. Doug ZW, Yan C, Yi W, Ciu YQ. Detection of congenital cytomegalovirus infection by using chorionic villi of the early pregnancy and polymerase chain reaction. Int J Gynaecol Obstet 1994;44:229-231. 